\title{
Recorregut de recerca geològica per la comarca del Vallès Occidental: des de Sentmenat al Castell de Guanta
}

Josep Maria Mata-Perelló

Joaquim Sanz Balagué

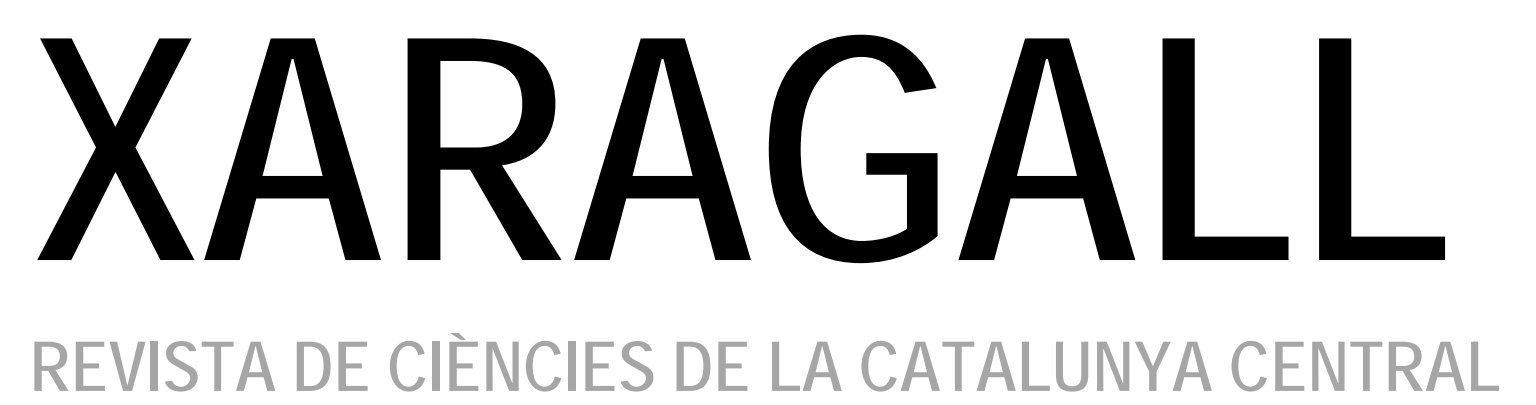

\section{n. 1}

GENER 2015 


\section{RECORREGUT DE RECERCA GEOLÒGICA PER LA COMARCA DEL VALLÈS OCCIDENTAL: DES DE SENTMENAT AL CASTELL DE GUANTA}

\section{Josep Maria Mata-Perelló}

Museu de geologia Valentí Masachs, Escola Politècnica Superior d'Enginyeria de Manresa (EPSEM), Universitat Politècnica de Catalunya · BarcelonaTech (UPC), 08272 Manresa, Spain

\section{Joaquim Sanz Balagué}

Departament d'Enginyeria Minera i Recursos Naturals (EMRN), Escola Politècnica Superior d'Enginyeria de Manresa (EPSEM), Universitat Politècnica de Catalunya - BarcelonaTech (UPC), 08272 Manresa, Spain

Paraules clau: Sistema Mediterrani, Patrimoni miner

\section{Resum}

Itinerari realitzat el 15 de febrer de 2014. En aquesta ocasió, el recorregut de l'itinerari discorrerà, en la seva totalitat pel Sistema Mediterrani, i més concretament per la Serralada Prelitoral Catalana (la seva unitat més externa). Així doncs, la quasi totalitat del recorregut per les vessants SE del Farell, per aquesta unitat geològica.

Per altra banda, i com ja s'entreveu al títol, el recorregut de l'itinerari discorrerà sols per la comarca del Vallès Occidental, pel terme de Sentmenat, en la seva totalitat, també. 


\section{Objectius fonamentals}

Els objectius fonamentals que es pretenen aconseguir en aquest itinerari, es poden concretar en els següents aspectes generals:

1. Observació i descripció dels materials mesozoics (del Triàsic, exclusivament) i paleozoics (fonamentalment de I'Ordovicià) de la Serralada Prelitoral Catalana, que es troben al llarg de bona part del recorregut de l'itinerari.

2. Observació de les estructures locals d'aquests materials, al llarg del recorregut de l'itinerari. Així com de les relacions entre les diferents unitats geològiques on es troben situades.

3. Observació dels diferents elements del Patrimoni Geològic (i si s'escau del Patrimoni Miner), que es vagin trobant al llarg del recorregut de l'itinerari.

\section{Antecedents}

Pel que fa al recorregut del present itinerari, cal dir que no hem sabut trobar cap antecedent bibliogràfic publicat, en relació al mateix. Nosaltres mateixos, és la primera vegada que realitzem un recorregut geològic per aquests indrets.

Pel que fa a la descripció de les mineralitzacions, farem esment del treball del mateix autor del present itinerari, Mata-Perelló (1991), relatiu al conjunt de les mineralitzacions catalanes.

I, finalment, pel que fa a l'estructura geològica de la zona per la qual discorre l'itinerari, farem esment dels treballs de: Guimerà et altri (1982) i de Riba et altri (1976); així com del full 392 de I'IGME (1976).

Tots aquests treballs referenciats, i d'altres, figuren esmentats per ordre alfabètic a l'apartat dedicat a la BIBLIOGRAFIA.

\section{Recorregut de l'itinerari}

La totalitat del recorregut de l'itinerari es situarà dintre de la comarca del Vallès Occidental. És més, la pràctica totalitat del mateix es realitzarà pel terme municipal de Sentmenat.

Així, s'iniciarà al mateix poble de Sentmenat (i més concretament a la carretera que condueix cap a Castellar del Vallès). Des d'aquesta, caldrà prendre el trencall que es dirigeix cap a Guanta.

Així, la totalitat d'aquest itinerari es realitzarà per la carretera (inicialment asfaltada i posteriorment de terra), que es dirigeix cap al Castell de Guanta, per on finalitzarà aquest recorregut. Cal dir que al llarg del mateix es faran diverses aturades. 


\section{Advertiments previs}

Com en altres recorreguts de RECERCA GEOLÒGICA I MINERALÒGICA... si es disposa del temps suficient, poden efectuar-se passant per totes les parades i filloles. En cas contrari, recomanem prescindir de les anomenades PARADES - CONDICIONALS.

En aquest itinerari, la totalitat del mateix es realitzarà per camins de muntanya i també per alguns trams de carretera; encara que en aquest cas serà mínim.

Com en tots els altres itineraris, recomanem tenir una cura molt especial de respecte a la natura, al llarg de tot el recorregut del mateix.

\section{Descripció de l'itinerari}

Com de costum, estructurarem el recorregut de l'itinerari en una sèrie de PARADES, que tot seguit anirem veient. En cadascuna d'aquestes aturades farem un breu comentari. En cada cas indicarem, entre parèntesi, el full topogràfic on es troba l'aturada, i la designarem amb el nom d'algun topònim proper, fent esment també del terme municipal on es troba situada. Finalment, cal dir que el recorregut de l'itinerari s'inclourà totalment dintre del full $n^{\circ} 392$ (o de Sabadell), del "Mapa Topográfico Nacional", realitzat a l'escala 1:50.000 per I'Instituto Geográfico y Catastral de España. També s'utilitzarà el mapa comarcal del Vallès Oriental, a escala 1:50.000, editat per I'Institut Cartogràfic de Catalunya.

Així, les diferents aturades que anirem trobant al llarg del recorregut, d'acord amb el seu ordre, seran les següents.

\subsection{Parada 1. CAMI - CARRETERA A GUANTA, IMMEDIACIONS DEL TRENCALL DE CAN SENOSA, (terme municipal de Sentmenat, comarca del Vallès Occidental). (Full 392).}

El recorregut de l'itinerari el començarem a la cruïlla de la carretera autonòmica $C$ - 1415a

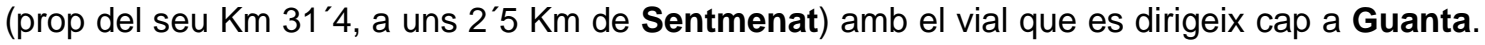
A partir d'aquest indret, ens convindrà fer un curt recorregut per aquesta carretereta, fins a sobrepassar lleugerament el barranc de Montllor. Per aquest indret, farem la primera aturada.

Aquest recorregut I'haurem efectuat en bona part entre afloraments dels materials paleozoics de l'Ordovicià, els qual s' hauran fet palesos a diferents indrets del recorregut, com per exemple al de l'indret de la present aturada, per on hi ha un aflorament dels esquistos de l'Ordovicià. (fotografia 1). 


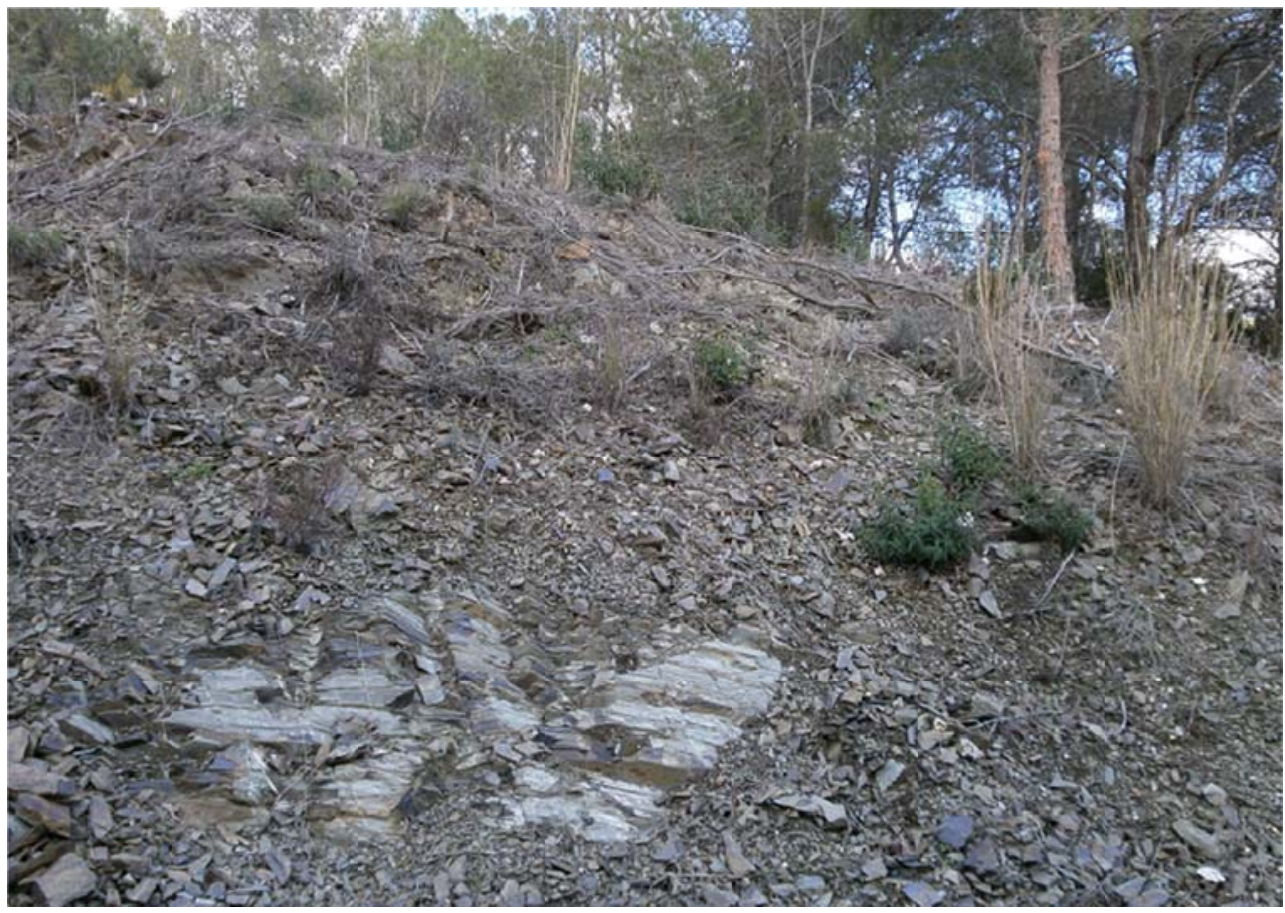

Fotografia 1. Aflorament dels esquistos de I'Ordovicià. Carretera de Sentmenat a Guanta

Tot i així, haurem començat el recorregut a l'extrem septentrional de la Depressió Prelitoral Catalana, entre afloraments dels materials terrígens del Miocè, coberts per depòsits detrítics del Pleistocè i de l'Holocè. Ben aviat, haurem sobrepassat la falla septentrional del Vallès Penedès, que no haurem vist, en trobar-se fossilitzada pels materials quaternaris acabats d'esmentar. En trobar i sobrepassar la fractura, haurem entrat a la Serralada Prelitoral Catalana, on ara estem situats.

Tot i no fer-se molt palesa aquesta fractura, immediatament, haurem començat a trobar els materials paleozoics de l'Ordovicià, esmentats anteriorment. Molt ocasionalment, haurem vist afloraments dels materials granítics del Carbonífer, molt alterats i convertit en sauló.

Per d'altra banda, en la part inicial del recorregut, mirant cap a ponent, s' haurà fet palès el Puig de la Creu, per on afloren els materials triàsics del Muschelkalk Inferior, prop del seu cim. (fotografia 2). 


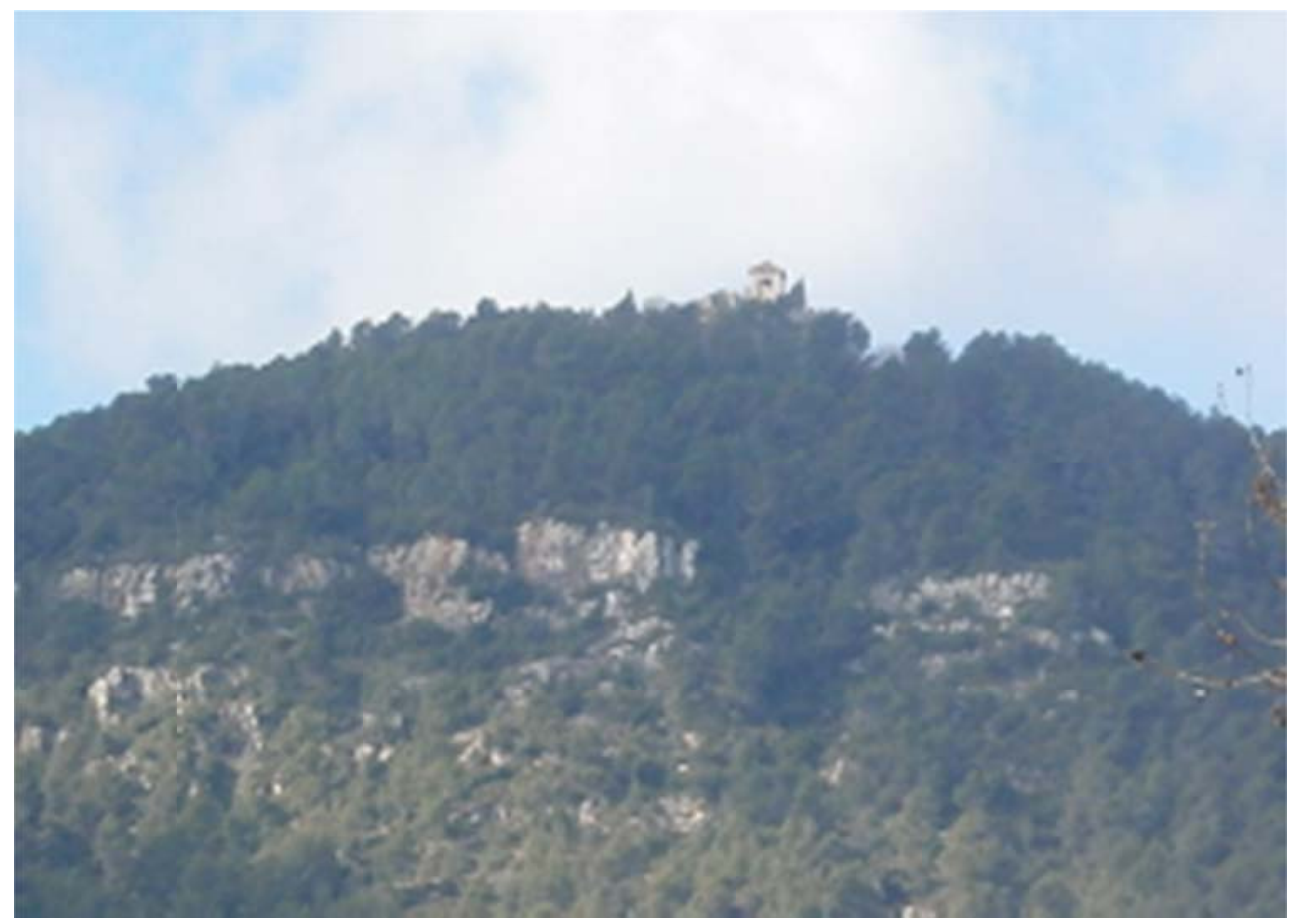

Fotografia 2. Aflorament de les calcàries del Muschelkalk Inferior, del Puig de la Creu. Carretereta de Sentmenat a Guanta

\subsection{Parada 2. CAMI - CARRETERA A GUANTA, IMMEDIACIONS DEL TRENCALL AL PONT DE SENOSA. (terme municipal de Sentmenat, comarca del Vallès Occidental). (Full 392).}

Després de realitzar la parada anterior, cal fer un nou recorregut per la carretereta que es dirigeix cap a Guanta. Aquest vial aviat deixa d'estar asfaltat, però te un bon pis. Aviat, es deixarà per la dreta el trencall que es dirigeix cap a Can Senosa. Després, ell vial començarà a pujar més ràpidament. En arribar a les immediacions del trencall del sender que condueix cap el Pont de Can Senosa (a uns 200 metres abans), farem una nova aturada. Així, haurem recorregut uns $2 \mathrm{Km}$ des de la parada anterior.

En aquest recorregut, hem anat trobant afloraments dels materials paleozoics de I'Ordovicià, que hem comentat al recorregut cap a la parada anterior. Aquests materials, també apareixen a l'indret on ara ens trobem situats.

Tot $\mathrm{i}$ això, aquests materials es troben en contacte amb els nivells inferiors del Triàsic; concretament amb els conglomerats quarsosos del Buntsandstein Inferior. Aquests contacte és netament discordant, molt palès a l'indret de l'aturada. (fotografia 3). 


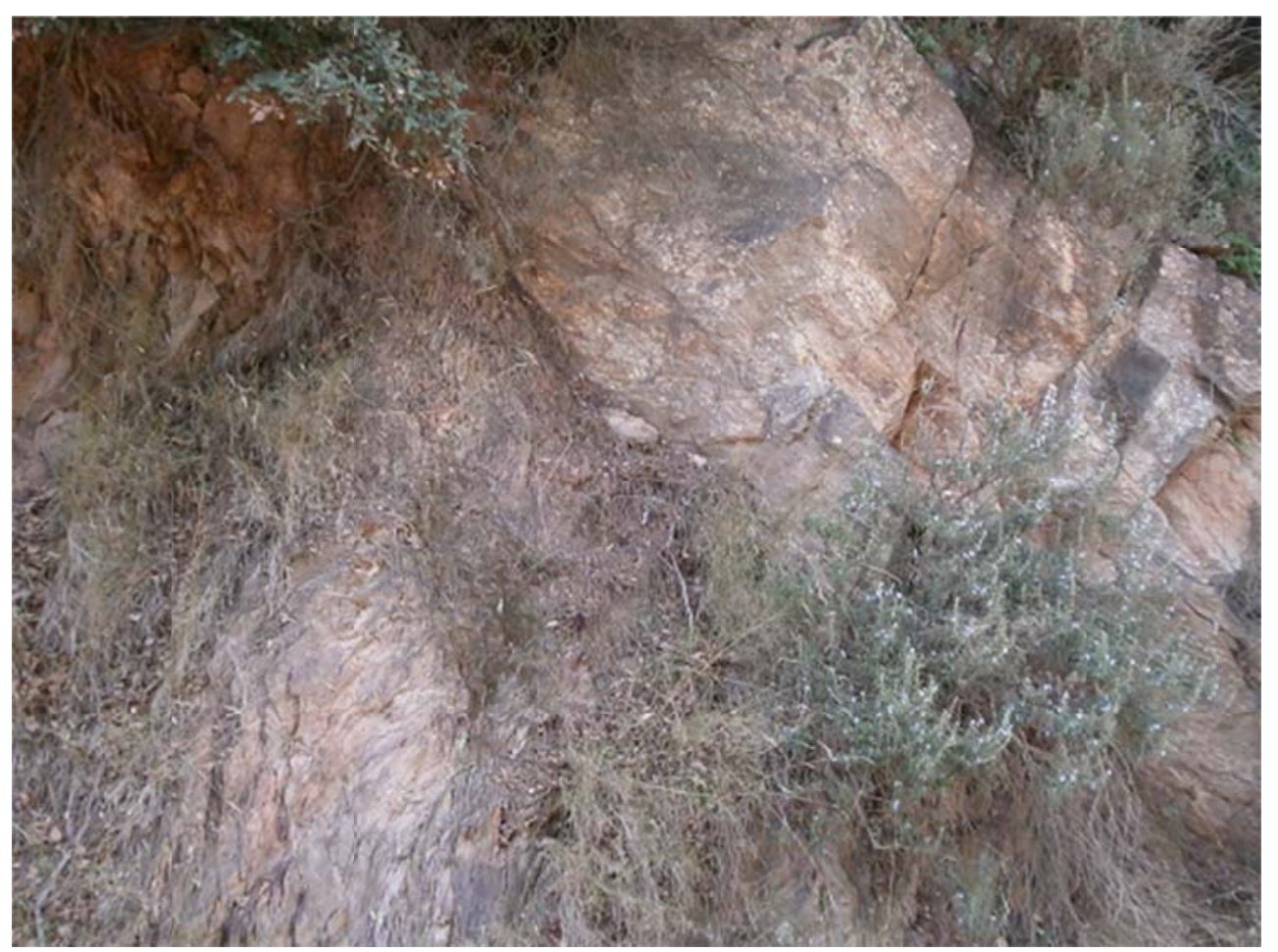

Fotografia 3. Contacte discordant entre els materials paleozoics, els esquistos de l'Ordovicià, (au la nostra esquerra) i els conglomerats i gresos triàsics del Buntsandstein (a la nostra dreta).

Vial cap a Guanta

Cal dir que a poca distància d'on haurem fet aquesta aturada, s'haurà començat a fer ben palès Guanta, en fer una corba del vial que estem recorrent.

\subsection{Parada 3. CAMÍ CARRETERA A GUANTA, IMMEDIACIONS DEL TRENCALL DEL CAMÍ AL COLL ROSSINYOL, (Guanta, terme municipal de Sentmenat, comarca del Vallès Occidental). (Full 392).}

Després de realitzar l'aturada anterior, cal continuar pel vial cap a l'indret de Guanta. Immediatament, superarem el trencall del sender que es dirigeix cap el Pont de Senosa (per la dreta). Més endavant, arribarem a l'indret on hi ha el trencall del camí que es dirigeix cap el Coll Rossinyol, per l'esquerra. Ben prop d'aquest trencall, un cop sobrepassat, farem una nova aturada, molt prop de Guanta. Així, des de la parada anterior, haurem recorregut ben prop de 2 $\mathrm{Km}$.

En aquest recorregut, hem anat trobant en tot moment els materials triàsics del Buntsandstein. Així, haurem vist els nivells dels gresos i de les calcolutites de tonalitats rogenques. Sovint, en observar els nivells del gresos, haurem vist bons exemples de laminació creuada.

Tot i així, en sobrepassar el vial del Coll de Rossinyol, s'hauran fet molt palesos els afloraments dels nivells carbonatats del Muschelkalk Inferior. Així, al costat del vial, haurem trobat els afloraments de les calcàries i de les dolomies del Triàsic Mig. Aquests materials es present en bancs potents, amb un lleuger capbussament cap el NW. (fotografia 4). 


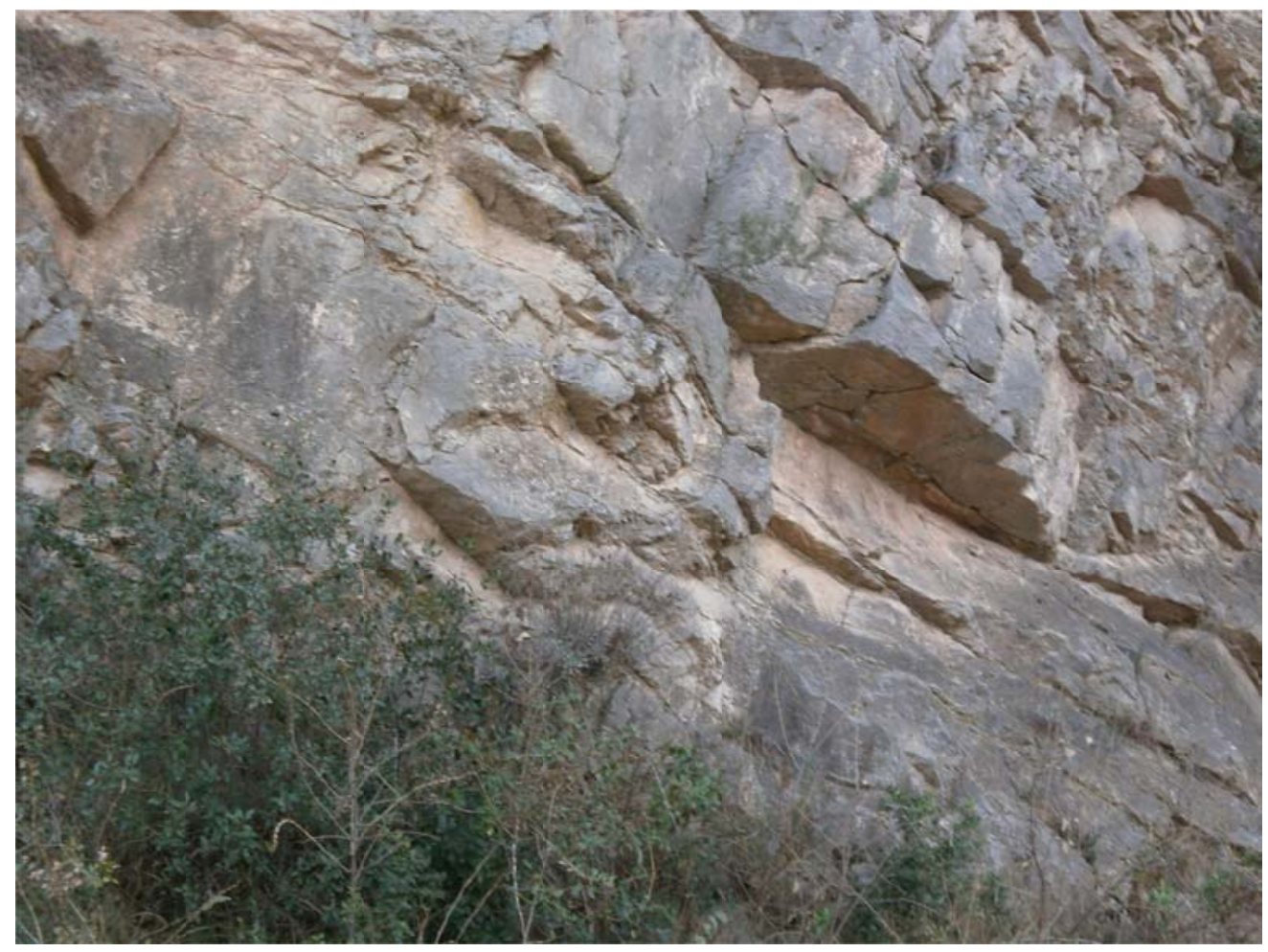

Fotografia 4. Aflorament dels materials carbonatats del Muschelkalk Inferior (Triàsic Mig) al vial de Guanta

Per altra banda, des d'on estem ara situats, mirant cap al Nord del camí (i també cap el NNE) es pot veure molt clarament on es troba Guanta. Efectivament, aquest prominent casalot, es troba sobre un aflorament dels materials carbonatats que acabem ara de veure. (fotografia 5) 


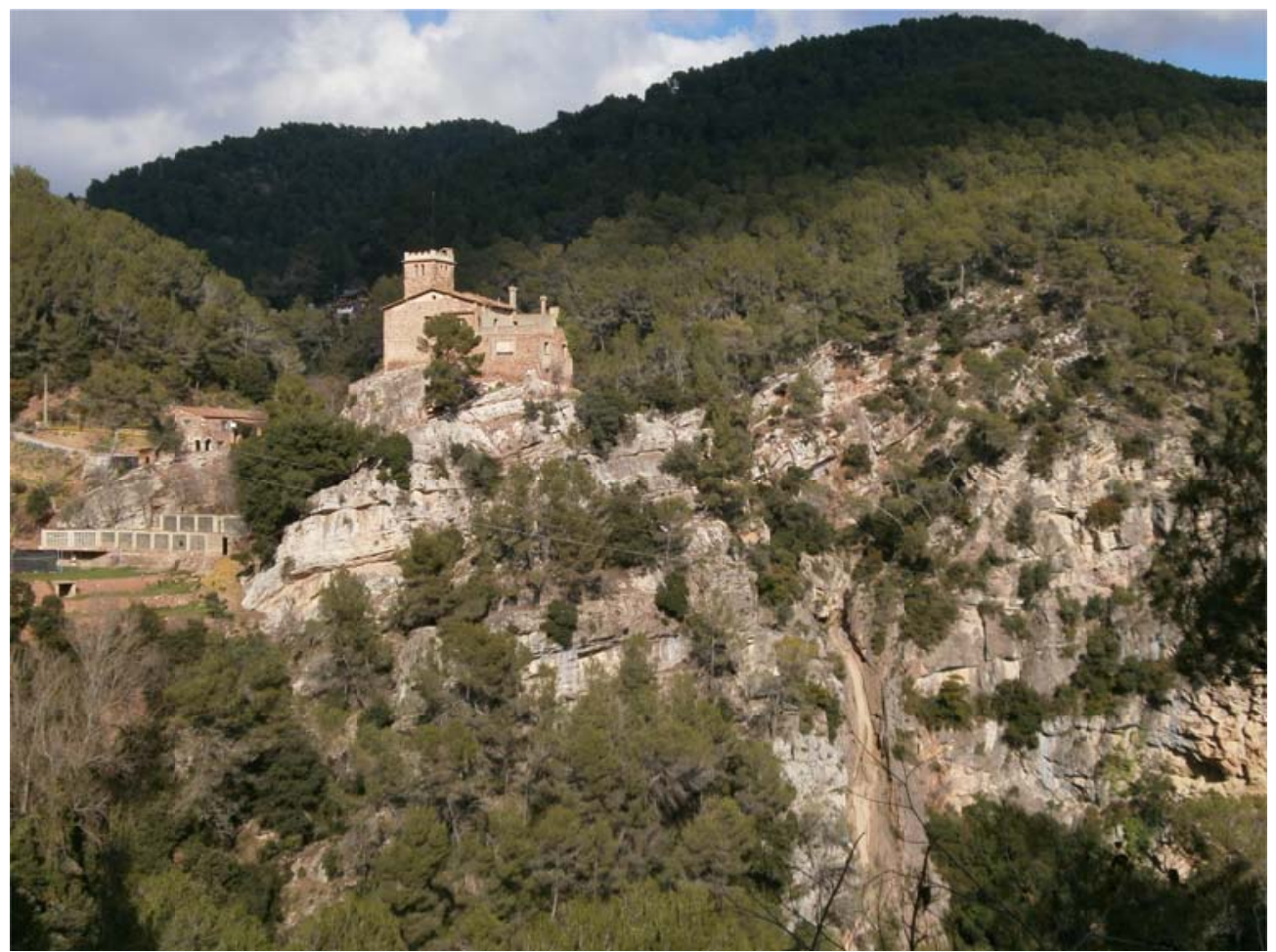

Fotografia 5. El Casalot de Guanta, sobre I'aflorament dels materials carbonatats del Muschelkalk Inferior. A la dreta de la casa es pot veure el Salt de Guanta

També, des d'aquest indret, es pot veure molt clarament el cabussament NW que presenten aquests materials, de forma que cap a llevant es van enlairant, constituint bona part del Bosc de Guanta.

També es pot veure que Guanta es troba sobre un interessant paratge, molt pintoresc, situat al costat del Torrent de Guanta, que en aquest indret, en trobar-se les calcaries del Muschelkalk Inferior, les supera, mitjançant un sallent molt vistós, I'anomenat Salt de Guanta, al costat oriental del casalot.

\subsection{Parada 4. CAMÍ CAP EL BOSC DE GUANTA, (Guanta, terme municipal de Sentmenat, comarca del Vallès Occidental). (Full 392).}

Després de realitzar l'aturada anterior, cal continuar cap al proper casalot de Guanta, molt proper d'on ens trobem ara situats. Després de sobrepassar la cruillla, des la qual surt per I'esquerra un bon camí que es dirigeix cap al NNW, cap el Turó dels Tres Pins, per l'esquerra. Nosaltres continuarem pel vial principal, cap el casalot, convertit en restaurant. Poc després de sobrepassar-lo (menys de 50 metres), farem la darrera aturada d'aquest itinerari. Així, des de la darrera parada, haurem efectuat un recorregut proper als 0’ $8 \mathrm{Km}$, aproximadament.

En aquest recorregut, haurem trobat inicialment, quasi fins al mateix indret de l'aturada, els materials carbonatats que hem vist a l'aturada anteriors; és a dir els nivells de les calcaries ( $\mathrm{i}$ molt ocasionalment de les dolomies) pertanyents al Triàsic Mig; concretament del Muschelkalk Inferior. 
Tot i així, en aquest indret, per sobre dels anteriors materials, es fan netament palesos uns afloraments de gresos i de calcolutites de tonalitats rogenques. Es tracta dels materials del Muschelkalk Mig (del sovint conegut com a tram roig del Muschelkalk). Aquests materials del Triàsic Mig, apareixen molt clarament al costat del camí, que ara es dirigeix cap el Bosc de Guanta. (fotografia 6).

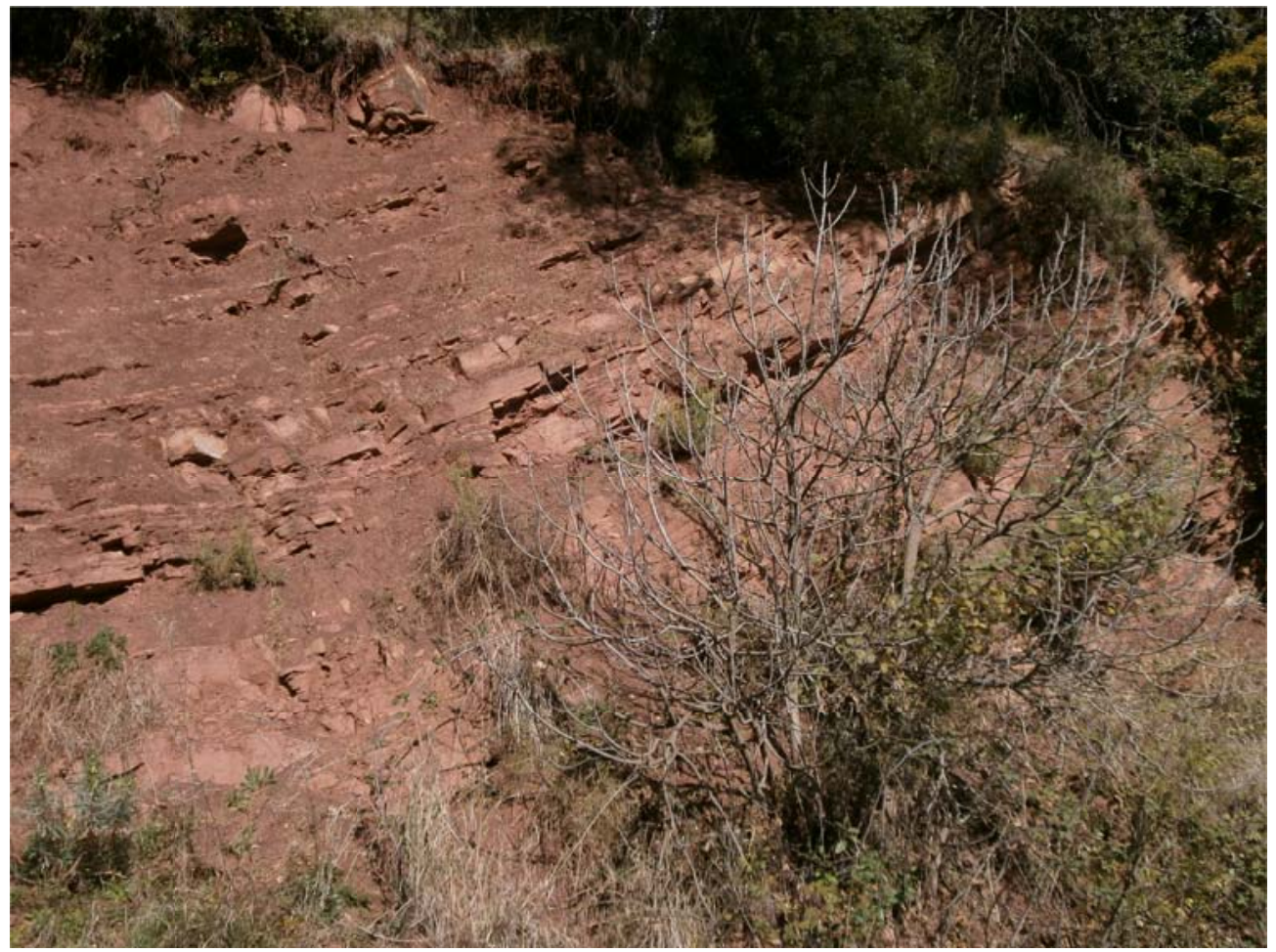

Fotografia 6. Aflorament dels gresos i calcolutites del Muschelkalk Mig, prop de la part allta de Guanta

En aquest indret finalitza el recorregut de l'itinerari.

\section{Bibliografia}

GUIMERÀ, J. et altri (1992).- Geologia (II), Història Natural dels Països Catalans, Vol.2, 547 pag. Enciclopèdia Catalana, S.A. Barcelona.

IGME (1976).- Mapa Geológico de España a escala 1:50.000 (segunda Série). Hoja y memória de la hoja no 392 (Sabadell). Inst. Geol. Minero de España. Minist. Indústria. Madrid.

MATA - PERELLÓ, J.M. (1991).- Els Minerals de Catalunya. Arxius de la Secció de Ciències, t. XCIII, 442 pag. Institut d’Estudis Catalans. Barcelona.

RIBA, O. et altri (1976).- Geografia Física dels Països Catalans, Edit. Ketres, 217 pag. Barcelona. 